\title{
Effectiveness of Direct Observation of Procedural Skills (DOPS) in Postgraduate Training in Urology at Institute of Kidney Diseases, Peshawar
}

\author{
Liaqat Ali1 ${ }^{1}$ Saima Ali², Nasir Orakzai ${ }^{1}$ and Naila Ali ${ }^{3}$
}

\begin{abstract}
Objective: To determine the effectiveness of direct observation of procedural skills (DOPS) in the assessment and improving operative skills of postgraduate residents in urology.

Study Design: Comparative study.

Place and Duration of Study: Department of Urology, Institute of Kidney Diseases (IKD), Hayatabad Medical Complex, Peshawar, from March till December 2016.

Methodology: Twenty postgraduate residents in urology were assessed for three commonly performed procedures in urology with structured proforma, specially designed for DOPS, using Likert scale from 1 to 5 . Formative feedback was given to all the residents highlighting their strengths and weaknesses. During second phase, all the three procedures were performed by four consultants respectively with residents as learner in the second phase of DOPS. During the third phase, a repeat assessment of e-residents was performed to study the overall improvement in operative skills, respectively.

Results: In pre-DOPS assessment, only 7 (35\%) out of 20 residents, passed in skill of cystoscopy, 6 (30\%) residents passed in transurethral resection of prostate (TURP), while $3(15 \%)$ residents passed in skills of uretero-renoscopy (URS). The mean score of overall ability to perform procedure during first phase of DOPS were $2.7 \pm 1.3$ for cystoscopy, $2.1 \pm 0.97$ for TURP, and $2.5 \pm 1.1$ for ureterorenoscopy. Significant improvement ( $p 0.04$ ) in passing was observed in third phase with $17(85 \%), 14(70 \%)$, and $14(70 \%)$ residents were declared passed in cystoscopy, TURP and URS, respectively. The mean score of overall ability to perform procedure during the third phase was $4.7 \pm 0.7$ for cystoscopy, $4.5 \pm 0.94$ for TURP, and $4.7 \pm 0.94$ for ureteroscopy.

Conclusion: DOPS is effective tool for assessing and improving the skills of postgraduate residents in urology.
\end{abstract}

Key Words: Direct observation of procedural skills (DOPS), Postgraduate medical education. Workplace assessment skills, Urology.

\section{INTRODUCTION}

Evidence-based medicine EBM is defined as the "evolution of medical sciences using special skills in order to integrate best available evidence and clinical expertise for caring individual patient". 1 This is as applicable to urology as to other fields including its training. The competency-based training programme follow any of the work-place based assessment (WPBA) tools like performance observation, 360 degree evaluation, objective structured clinical examination, mini-clinical evaluation exercise (Mini-CEX), and direct observation of procedural skills (DOPS). ${ }^{2-5}$ DOPS is a method of evaluating procedural skills of a trainee

1 Department of Urology, Institute of Kidney Diseases (IKD), Hayatabad Medical Complex, Peshawar, Pakistan

2 Department of Paediatric Medicine, Peshawar Medical College, Peshawar

3 Department of Ophthalmology, Faraday Gardens Wolverhampton, WV3, 9EQ, UK.

Correspondence: Dr. Liaqat Ali, Department of Urology, Institute of Kidney Diseases (IKD), Hayatabad Medical

Complex, Peshawar, Pakistan

E-mail: liaqat_99@yahoo.com

Received: August 20, 2018; Accepted: December 20, 2018 through observation in the workplace. ${ }^{2}$ It is conducted at three levels with specified time intervals. The evaluator gives feedback to student and mentions their strengths and weaknesses. At the end of the third level, the evaluator rates the students' performance by using a structured checklist and gives them feedback. ${ }^{5}$ The importance of introducing DOPS in improving urological training can be ascertained by the fact that recent studies have shown increasing rate of iatrogenic urethral injuries, ${ }^{6}$ and current practices are not up to the mark because of obsession with objectivity; and almost $50 \%$ of students are not observed while performing clinical examination. The trainees do not receive any productive feedback for their surgical skills in $80 \%$ of cases. ${ }^{7}$

The rationale of our present study is based upon the observation of the growing interest of College of Physicians and Surgeons Pakistan (CPSP) in getting evidence regarding which tool is more preferred in the assessment of surgical skills in urology residency programme. DOPS has been designed at the study place to provide feedback on procedural skills essential to the provision of good clinical care.

The objective of the study was to determine the effectiveness of DOPS in assessment and improvement of operative skills of postgraduate residents in urology. 


\section{METHODOLOGY}

It was a comparative study that was conducted in Department of Urology Team "C", Institute of Kidney Diseases, Hayatabad Medical Complex, Peshawar from March to December 2016. Inclusion criterion was the residents who have mentioned in their log books that had performed at least 10 cases of cystoscopy, transurethral resection of prostate (TURP), and ureterorenoscopy (URS). All the residents who were on the rotation from other surgical disciplines were excluded from the study. A standardised structured proforma was used for these procedure, using Likert scale of 1-5 with 1 = insufficient evidence, 2 = below expectation for completion, 3 = boarderline for expectation, $4=$ meets expectation, and 5 above expectation. Minimum of $60 \%$ as per CPSP rules, was considered passing marks for all the three procedures.

Eight parameters were checked that included demonstration of understating of indication, relevant anatomy and technique, pre-procedure preparation, aseptic techniques, technical ability, post-procedural management, communication skills, consideration of patient and professionalism, and the overall ability to perform the procedure.

The study was conducted in three phases with one month interval. During the first phase of the study, residents were assessed with structured DOPS proforma using Likert scale of 1-5, and feedback were given to all the residents about their strength and weaknesses of procedure. During the second phase, all the three procedures were performed by four consultants of assistant professor level, and above possessing fellowship in urology under standardised checklist, respectively. The residents were allowed as first assistants or observers for all the procedures for one month. Finally, during third phase, the residents were finally assessed again with proforma.

All the data were analysed on SPSS version 17. Pearson Chi-square test was used to analyse the frequency of pass percentage in phase 1 (pre-DOPS) and phase 3 (post-DOPS).

\section{RESULTS}

Twenty residents participated in the study. Six (30\%) residents were in their first year, $6(30 \%)$ were in second year, while $8(40 \%)$ were in third year of residency programme. In the first phase, pre-DOPS assessment, out of 20 residents, only $7(35 \%)$ residents passed in skill of cystoscopy, $6(30 \%)$ residents passed in TURP, while $3(15 \%)$ residents passed in skills of URS. Majority of residents fail to satisfy their team of consultants by scoring less than $60 \%$ of desired marks. Formative feedback of strengths and weaknesses were communicated to all the residents in formative way. The summary of weaknesses of the postgraduate residents is shown in Table I.
Table I: Weaknesses of residents in different parameters for cystoscopy during 1 st phase of DOPS.

\begin{tabular}{l|c|c|c}
\hline Parameters & Mean & Standard deviation & Scale \\
\hline Consideration of patient/professionalism & 1.8 & 0.9 & $1-5$ \\
Communication skills & 1.9 & 1.1 & $1-5$ \\
Scrubbing and draping & 1.9 & 1.0 & $1-5$ \\
Aseptic techniques & 2.2 & 1.0 & $1-5$ \\
Seeking help when appropriate & 2.3 & 1.0 & $1-5$ \\
Post-procedure management & 2.3 & 1.0 & $1-5$ \\
\hline
\end{tabular}

Table II: Comparative results of Pre-DOPS (Phase 1) and Post-DOPS (Phase 3).

\begin{tabular}{l|l|cc|cc|c}
\hline $\mathrm{N}$ & \multirow{2}{*}{ Procedure } & \multicolumn{2}{|c|}{ Pre-DOPS } & \multicolumn{2}{c|}{ Post-DOPS } & $\begin{array}{c}\text { Pearson } \\
\text { Chi-square } \\
\text { test }\end{array}$ \\
\cline { 3 - 7 } & & Pass & Fail & Pass & Fail & $\mathrm{p} 0.04$ \\
\hline 20 & Cytoscopy & $07(35 \%)$ & $13(65 \%)$ & $17(85 \%)$ & $03(15 \%)$ & \\
20 & TURP & $06(30 \%)$ & $14(70 \%)$ & $14(70 \%)$ & $06(30 \%)$ & \\
20 & URS & $03(15 \%)$ & $17(85 \%)$ & $14(70 \%)$ & $06(30 \%)$ & \\
\hline
\end{tabular}

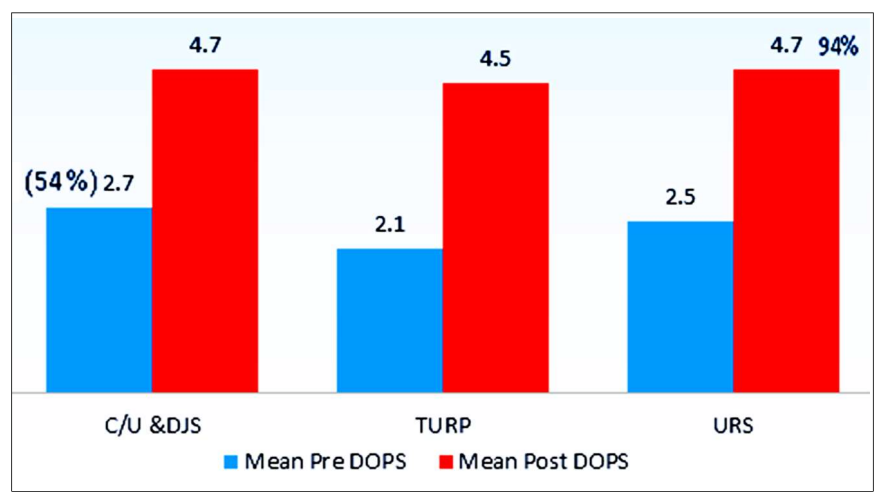

Figure 1: Bar graph showing comparison of mean pre- and post-DOPS range (1-5) of Likert scale.

The mean strengths of postgraduate residents in different variables were found to be surgery, pre-procedural preparation, and technical ability by $4.1 \pm 0.71,3.9 \pm 0.78$ and $4.4 \pm 0.75$, respectively. The mean over all ability to perform the procedure in Phase 1 was 2.7, 2.1 and 2.5 for cystoscopy, TURP, and URS, respectively. Similar observations of weaknesses and strengths of residents were observed in TURP and URS. Repeat DOPS showed significant improvement pass percentage as compared to the phase 1 (Table II).

The mean improvement in overall ability to perform procedures is shown in Figure 1. The mean time duration for feedback by consultants was $7.5 \pm 3.2$ minutes for all the procedures.

\section{DISCUSSION}

Postgraduate teaching is directed not only at attainment of knowledge, attitude, and skill; but also towards responsiveness and proper functioning in real life situations. It is known that controlled situations in conventional assessment during examination settings usually fail to measure these outcomes. ${ }^{8}$

DOPS is a new emerging and valuable tool in armamentarium of workplace based assessment. Its importance is 
based on emphasis that it equally touches all the domains of Bloom's taxonomy. The competence-based assessment for the psychomotor domain of surgical skills can be assesse in reasonable time and invariably results in overall improvement in all domains of knowledge, attitude and skills.

The strength of this study is that, it is in fact the first study in present setup with more objective assessment tools for DOPS. The weakness is relatively lesser number of urology residents. Although our results have shown promising results in overall improvement in residents, yet it cannot be generalised in other surgical disciplines.

The growing number of residents in urological discipline by College of Physicians and Surgeons Pakistan, has placed a great responsibility on the Faculty members to train the residents and play crucial role in promoting evidence-based teaching in urology. This mechanism can help in standardisation of teaching programme across the country. DOPs are designed for the residents to ensure that a particular surgical skill is performed correctly, according to agreed guidelines using an agreed checklist.

Morris et al. concluded that DOPS possesses significant positive feedback and result in improving competencebased learning in house surgeons in different years of foundation. ${ }^{2}$ Seventy percent of the respondents labelled DOPS very useful in their overall improvement of procedural skills. The same findings were also observed in this study, too.

Other medical disciplines took a lead in starting DOPS with positive innovative intention, as McLeod has concluded DOPS as very valuable tool in undergraduate medical students in UK. ${ }^{9}$ Hill and colleagues have found DOPS very successful as $90 \%$ of the residents scored 17 out of 30 marks for ultrasound-guided central line insertion in anesthesia department.10 Profanter and Perathoner in their benchmark study have concluded DOPS as an efficient tool as compared to OSCE and Mini-Cx. In their study, 320 DOPS were performed. The statistical analysis of DOPS items amounted to $92.4 \%$ improvement in surgical skills. ${ }^{11}$ Kumar proved significant improvement in pre- and post-DOPS analyses for different gynaecological procedures. ${ }^{12}$ She concluded that DOPS offers high level of satisfaction and improvement in surgical skills for postgraduate trainees. DOPS has been found effective in improving skills of residents of General Surgery as well.2,13,14

There is little research work of effictiveness of DOPS in urological disciplines and the present study is probably the first in determining the DOPS in urology in real time operation room scenarios. However, Hung studied effectiveness of DOPS in trans-rectal ultrasound for estimation of size of prostate as well as abnormal findings concluded significant relation $p<0.05$ in favour of DOPS. 15 Same results were also recorded in this study with significant result in favour of pre- and postDOPS analyses of 0.002 for different urological procedures.

The mean time for the feedback of DOPS in this study was 7.5 minutes, which is in accordance to the international literature for postgraduate residents and even better than undergraduate residents, where mean feedback time was 14 minutes. Naina Kumar have also mentioned DOPS as successful modality with rapid feedback in the form of both marks, immediate and relevant feedback for postgraduate residents. 12,14,16

This study is implicated on all the faculty members of CPSP who are supervisors for fellowship in urology. All the supervisors in urology should recognise the positive impact of DOPS in practical clinical and surgical scenarios. Due to the limited number of residents in this study, it is desirable to check the effectiveness of DOPS in multi-centres of Pakistan, recognised for postgraduate training in urology.

\section{CONCLUSION}

DOPS is an effective, efficient, and successful workplace-based assessment tool in improving surgical skills of residents in urology in real time operation room scenarios. Moreover, it provides constructive feedback to the residents in shorter period of time.

\section{REFERENCES}

1. Hajebrahimi S, Ali M. How to teach evidence-based medicine to urologists. Indian J Urol 2011; 27:490-3.

2. Waqar SH. Student's perception of direct observation of procedural skills as workplace-based assessment tool in general surgery. Pak Armed Forces Med J 2016; 66:731-7.

3. Morris A, Hewitt J, Roberts CM. Practical experience of using directly observed procedures, mini-clinical evaluation examinations, and peer observation in pre-registration house officer (FY1) trainees. Postgrad Med J 2006; 82:285-8.

4. Norcini JJ, Blank LL, Duffy FD, Fortna GS. The mini-CEX: A method for assessing clinical skills. Ann Intern Med 2003; 138:476-81.

5. Violato $\mathrm{C}$, Lockyer J, Fidler H. Multisource feedback: A method of assessing surgical practice. BMJ 2003; 326:546-8.

6. Hengameh H, Afsaneh R, Morteza K, Hosein M, Marjan SM, Abbas $E$. The effect of applying direct observation of procedural skills (DOPS) on nursing students' clinical skills: A randomized clinical trial. Glob J Health Sci 2015; 7:17-21.

7. Ali L, Hayat F, Orakzai N. An audit of genitourinary trauma at Institute of Kidney Diseases, Peshawar. J Med Sci 2018; 26:58-62.

8. Ali L, Ghani A, Saifullah, Aslam M, Orakzai N. Basic knowledge of urology in undergraduate medical students: A KAP survey in 6 medical colleges of Khyber Pukhtunkhwa. J Med Sci 2017; 25:158-62.

9. Sahebalzamani $M$, Farahani $H$, Jahantigh $M$. Validity and reliability of direct observation of procedural skills in evaluating the clinical skills of nursing students of Zahedan nursing and midwifery school. J Res Med Sci (ZJRMS) 2012; 14:76-81. 
10. McLeod R, Mires G, Ker J. Direct observed procedural skills assessment in the undergraduate setting. Clin Teach 2012; 9:228-32

11. Hill K, Silcock D, Burns F, Jeffrey S, Chaudhri S. Use of a directly observed procedural skills assessment tool for candidate evaluation after an ultrasound-guided central line insertion workshop. Anesth Analg 2016; 123:93-4.

12. Profanter C, Perathoner A. DOPS (direct observation of procedural skills) in undergraduate skills-lab: Does it work? Analysis of skills-performance and curricular side effects. GMS Z Med Ausbild 2015; 32:45.

13. Khaliq T. Effectiveness of direct observation of procedural skills (DOPS) as an assessment tool in surgery. Pak Armed Forces Med J 2014; 64:626-9.
14. Naina K, Namit kant S, Samar R, Swanand P. Effect of formative evaluation using direct observation of procedural skills in assessment of postgraduate students of obstetrics and gynecology: Prospective study. J Adv Med Educ Prof 2017; 5:1-5.

15. Ke-Hung T, Chung-Yi L, Jui-Ming L, Shih-Tseng L, Rei-Ping T, Phei-Lang C. Direct observation of procedural skills to improve validity of student's measurement of prostate volume in predicting treatment outcomes. Urol Sci 2013; 24:84-8.

16. Larson JL, Williams RG, Ketchum J, Boehler ML, Dunnington GL. Feasibility, reliability and validity of an operative performance rating system for evaluating surgery students. Surgery 2005; 138:640-7. 